\title{
Increased phosphorylation of 4E-binding protein 1 predicts poor prognosis for patients with colorectal cancer
}

\author{
YUFENG MIAO ${ }^{1,2}$, LIGE CHEN $^{3}$, CUIFEN SHI $^{4}$, RENGEN FAN ${ }^{5}$, \\ PING CHEN $^{2}$, HONGQI LIU ${ }^{2}$, AIHUA XIA ${ }^{6}$ and HAIXIN QIAN ${ }^{1}$ \\ ${ }^{1}$ Department of General Surgery, The First Affiliated Hospital of Soochow University, Suzhou, Jiangsu 215006; \\ Departments of ${ }^{2}$ Medical Oncology and ${ }^{3}$ Pharmacy, Yancheng First People's Hospital, Yancheng, Jiangsu 224001; \\ ${ }^{4}$ Department of Hepatology, Yancheng No. 2 People's Hospital, Yancheng, Jiangsu 224002; Departments of \\ ${ }^{5}$ General Surgery and ${ }^{6}$ Clinical Laboratory, Yancheng First People's Hospital, Yancheng, Jiangsu 224001, P.R. China
}

Received November 11, 2015; Accepted December 23, 2016

DOI: $10.3892 / \mathrm{mmr} .2017 .6352$

\begin{abstract}
As demonstrated in previous studies, the phosphorylated form of $4 \mathrm{E}$-binding protein 1 (p-4E-BP1) may be a suitable tumor biomarker. The aim of the current study was to examine the expression status of $\mathrm{p}-4 \mathrm{E}-\mathrm{BP} 1$ in colorectal cancer (CRC), in order to determine its clinical significance. The present study enrolled 89 patients with CRC that had undergone radical resection. Paired tumor and adjacent normal tissues were evaluated using immunohistochemistry to detect the protein expression of $\mathrm{p}-4 \mathrm{E}-\mathrm{BP} 1$ and phosphatase and tensin homolog (PTEN). The study identified 53 cases (59.6\%) that exhibited moderate or high expression of p-4E-BP1 in tumor tissues, compared with little or no expression in the adjacent normal tissues. Conversely, PTEN protein expression was markedly lower in CRC compared with adjacent normal tissues. $\mathrm{p}-4 \mathrm{E}-\mathrm{BP} 1$ protein upregulation tissues samples was consistent with PTEN downregulation in CRC samples. p-4E-BP1 overexpression was predominant in patients with metastasis to the regional lymph nodes. Moderate/high expression of $\mathrm{p}-4 \mathrm{E}-\mathrm{BP} 1$ protein was significantly associated with adverse overall survival (OS) in patients. Statistical analysis using the Cox proportional hazards model, indicated that p-4E-BP1 expression was an independent factor suitable for predicting OS in CRC patients, which was independent of lymph node metastasis. In conclusion, $\mathrm{p}-4 \mathrm{E}-\mathrm{BP} 1$ protein expression appears to be upregulated in $\mathrm{CRC}$, suggesting that it may be a suitable biomarker for predicting CRC prognosis.
\end{abstract}

Correspondence to: Professor Haixin Qian, Department of General Surgery, The First Affiliated Hospital of Soochow University, 188 Shizi Road, Suzhou, Jiangsu 215006, P.R. China

E-mail: haixinqian@tom.com

Key words: colorectal cancer, phosphorylated 4E-binding protein 1, phosphatase and tensin homolog, prognosis

\section{Introduction}

Colorectal cancer (CRC) is a commonly occurring cancer, with approximately one million new cases diagnosed annually worldwide (1). In its early stages, the disease is curable with surgery, however $50-60 \%$ of patients diagnosed with CRC will develop metastases (2). In order to facilitate the development of more effective treatments for patients with CRC, prognostic and predictive markers need to be identified. Currently, tumor staging at the time of diagnosis and determination of histological grade, such as the tumor node metastasis (TNM) and the Duke's staging systems, are the two most important techniques.

Previous studies have identified several biomarkers in multiple tumor types that are associated with disease progression and clinical outcome. Among these established biomarkers, 4E-binding protein 1 (4E-BP1) is associated with cell signaling and downstream regulation of the mitogen-activated protein kinase (MAPK) signaling pathway and the phosphatidylinositol 3-kinase (PI3K)/protein kinase B (AKT)/mammalian target of rapamycin (mTOR) signaling pathway (3). 4E-BP1 is activated when phosphorylated by AKT and ribosomal protein S6 kinase B1, and serves a critical role in RNA translation and in the regulation of cell growth $(4,5)$. Previous studies have established that phosphorylated 4E-BP1 (p-4E-BP1) is involved in the initiation and progression of cancer. Therefore, p-4E-BP1 may be a suitable tumor biomarker. Certain types of tumor, including those of the esophagus, stomach, breast, ovary, uterine cervix and endometrium exhibit high expression levels of p-4E-BP1, which has been demonstrated to be associated with poor prognosis (6-11). However, the prognostic value of $\mathrm{p}-4 \mathrm{E}-\mathrm{BP} 1$ in $\mathrm{CRC}$ remains unclear. The aim of the present study was to assess the status of p-4E-BP1 in CRC specimens, and to establish its clinical significance. As phosphatase and tensin homolog (PTEN) is an important member of the PI3K/AKT signaling pathway, the association between p-4E-BP1 and PTEN expression was also examined.

\section{Materials and methods}

Study population. The present study enrolled 89 patients (48 men, 41 women; age range, 40-81 years; median age, 
58 years) with primary CRC that had undergone surgical resection during the period from February 2008 to June 2010 in Yancheng First People's Hospital (Yancheng, China). No patients had received preoperative treatment, such as radiation or chemotherapy. Tumor stage was assessed using the 2010 version of the TNM classification system (12), issued by the American Joint Committee on Cancer (AJCC). A total of 8 patients were at stage I, 30 at stage II, 45 at stage III and 6 at stage IV. Cellular differentiation was graded using the World Health Organization grading system (13). Clinical follow-up data was obtained for all patients. The study was approved by the ethical committee of Yancheng First People's Hospital, and all patients provided informed consent prior to sample examination.

Immunohistochemical analysis. A total of 89 pairs of $10 \%$ formalin-fixed, paraffin-embedded sections (thickness, $4 \mu \mathrm{m}$ ) of cancerous and adjacent non-cancerous tissues were prepared for immunohistochemical analysis. Serial tissue sections were deparaffinized with xylene, then rehydrated through grade alcohols and subjected to autoclave antigen retrieval in ethylenediaminetetraacetic acid buffer $\left(\mathrm{pH} \mathrm{8.0)}\right.$ at $100^{\circ} \mathrm{C}$ for $5 \mathrm{~min}$. Endogenous peroxidase activity was blocked by $3 \%$ hydrogen peroxide for $10 \mathrm{~min}$. Next, tissue sections were incubated at $4^{\circ} \mathrm{C}$ overnight with a rabbit monoclonal anti-p-4E-BP1 antibody (Thr 37/46, 236B4; dilution, 1:250; cat. no. 2855; Cell Signaling Technology, Inc., Danvers, MA, USA) or a rabbit anti-human PTEN monoclonal antibody (dilution, 1:250; cat. no. 9188; Cell Signaling Technology, Inc.). The samples were washed 3 times in PBS, and then treated for $2 \mathrm{~h}$ at $24^{\circ} \mathrm{C}$ with an EnVision peroxidase-labeled polymer antibody (Dako; cat. no. k4011, ready-to-use; Agilent Technologies, Inc., Santa Clara, CA, USA). The slides were developed for $8 \mathrm{~min}$ with 3,3'-diaminobenzidine (DAB) $/ \mathrm{H}_{2} \mathrm{O}_{2}$ chromogen and counterstained with hematoxylin for $5 \mathrm{~min}$. Omission of the primary antibody served as a control. A BX41 microscope (Olympus Corporation, Tokyo, Japan) was used to identify positive staining in the cytoplasm and was semi-quantitatively graded using the following three categories: $1+, 1-30 \%$ of the tumor cells were positive; $2+$, $\geq 30$ to $<60 \%$ of the tumor cells were positive; $3+, \geq 60 \%$ of the tumor cells were positive. All assays were performed at least in triplicate. Immunohistochemical results were determined by two independent pathologists.

Statistical analysis. Statistical tests were performed using SPSS software (version 16.0; SPSS Inc., Chicago, IL, USA). Differences in protein expression between groups were analyzed using Student's $t$-test. The chi-squared test was used to identify differences in frequency. Correlation between p-4E-BP1 and PTEN expression was determined by Pearson analysis. Overall survival (OS) was calculated using the Kaplan-Meier method, and OS values were compared using Mantell-Cox log-rank testing. The multivariate Cox proportional hazards model was used to establish the prognostic significance of each specific parameter. $\mathrm{P}<0.05$ was considered to indicate a statistically significant difference.

\section{Results}

p-4E-BP1 protein expression profiles in CRC. Fig. 1 presents representative immunohistochemical results of $\mathrm{p}-4 \mathrm{E}-\mathrm{BP} 1$ and
PTEN staining in CRC and adjacent normal tissue samples. A total of 65 CRC cases (73.0\%) demonstrated positive expression of the p-4E-BP1 protein, where 53 cases (59.6\%) exhibited moderate to high expression (grade $2+$ and $3+$ ). By contrast, p-4E-BP1 exhibited little or no expression in adjacent normal tissues. PTEN exhibited significantly lower expression in CRC samples when compared with normal tissues (moderate/high expression CRC, 16/89 vs. normal, 49/89; $\mathrm{P}<0.001)$. Upregulation of $\mathrm{p}-4 \mathrm{E}-\mathrm{BP} 1$ protein expression was associated with downregulated PTEN (r=-0.731; Fig. 2A).

Association between $p-4 E-B P 1$ protein expression and clinicopathological features. No correlations were observed between p-4E-BP1 protein expression and patient age, gender, tumor location, tumor diameter, local invasion (T stage) or clinical stage (Table I). Although the upregulation of p-4E-BP1 was more prevalent in patients with lymph node metastasis and poor differentiation, no statistical significance was observed (Table I).

Association between $p-4 E-B P 1$ protein expression and OS. Prior to the follow-up deadline, 42 patients did not survive 5 years following surgery. Univariate survival analysis indicated that CRC patients with moderate to high expression of the p-4E-BP1 protein demonstrated significantly shorter OS (mean 37.5 months, 95\% CI: 32.693-42.307) when compared with patients exhibiting little or no $\mathrm{p}-4 \mathrm{E}-\mathrm{BP} 1$ expression (mean 47.8 months, 95\% CI: 42.564-53.112; P=0.08; Fig. 2B).

Following adjustment for potential confounding cofactors, multiple Cox regression analysis indicated that high to moderate expression of the p-4E-BP1 protein was an independent factor for predicting adverse OS in patients, apart from lymph metastasis (Table II).

\section{Discussion}

CRC is the third most common cause of cancer-associated mortality worldwide, accounting for $8 \%$ of all cancer-associated deaths (1). The AJCC staging system is the current standard used for determining the prognosis of patients with cancer. Typically, patients with stage II and stage III disease, which are at risk of locoregional or distant relapse are treated using chemotherapy, whereas patient with stage I disease are treated using surgery alone (14). However, in patients undergoing surgery for localized CRC, pathological staging is unable to predict recurrence accurately, due to the highly heterogeneous phenotype of CRC (15). Cancer recurs in 10-20\% of patients with stage II disease and in 30-40\% of patients with stage III disease (16). Thus, molecular biomarkers have been extensively investigated with respect to the characterization and prognosis of CRC. The CpG island methylator phenotype, microsatellite instability, chromosomal instability, KRAS and BRAF mutations have been demonstrated to constitute an important prognostic system for CRC (17-19). Gene expression profiling has previously demonstrated considerable promise in predicting prognosis in individual patients with cancer. As a result, several gene expression signatures have been developed to classify specific prognostic groups beyond the clinicopathological features of CRC (20).

4E-BP1 binds eukaryotic initiation factor 4E (eIF4E) and serves a critical role in the control of protein synthesis, 

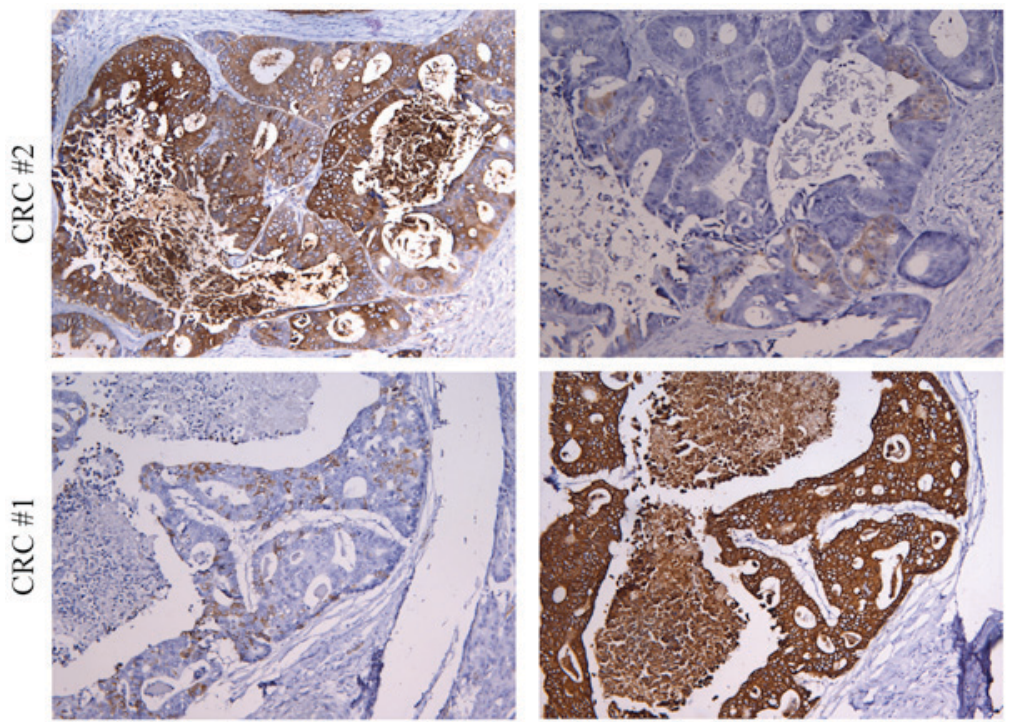

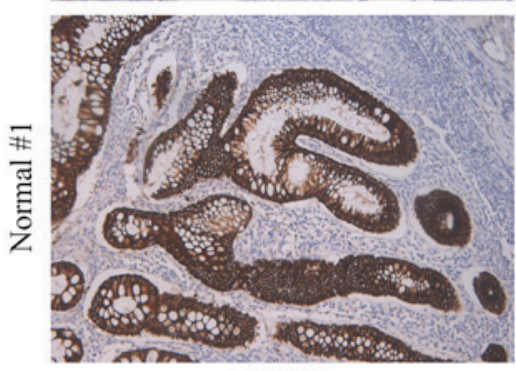

PTEN
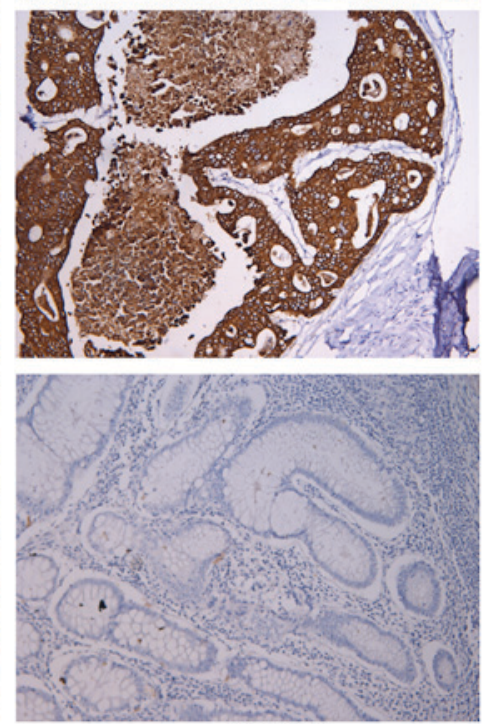

p-4E-BP1

Figure 1. p-4E-BP1 and PTEN expression in CRC and normal adjacent tissues determined by immunohistochemical staining (magnification, $\mathrm{x} 200$ ). Representative images of two CRC and one normal serial tissue sections demonstrating p-4E-BP1 and PTEN positive expression in the cytoplasm. CRC, colorectal cancer; p-4E-BP1, phosphorylated 4E-binding protein 1; PTEN, phosphatase and tensin homolog.
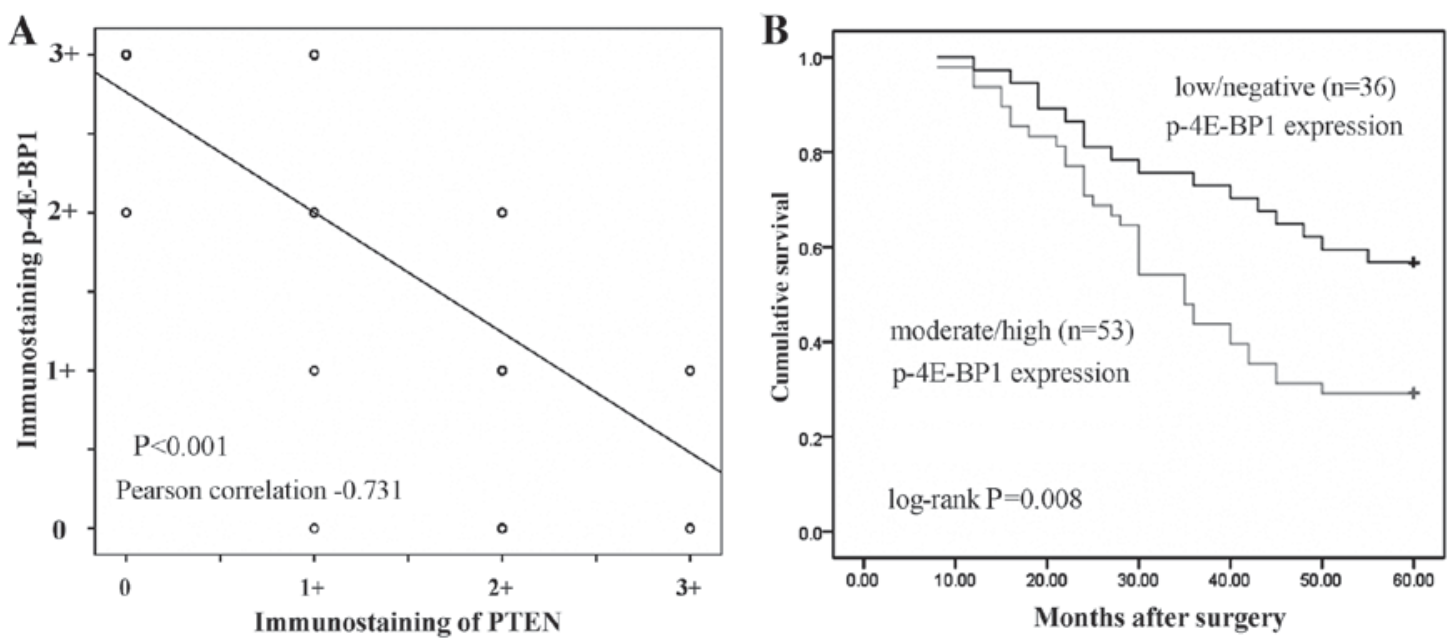

Figure 2. Kaplan-Meier analyses of OS in 89 CRC patients. (A) Correlation between p-4E-BP1 and PTEN expression in CRC tumor tissue samples as determined by immunohistochemical staining. The images were graded according to the following criteria: $1+, 1-30 \%$ of tumor cells were positive; $2+,>30$ to $<60 \%$ of tumor cells were positive; $3+, \geq 60 \%$ of the tumor cells were positive. (B) The 5 -year OS in patients with CRC that exhibit moderate/high expression of p-4E-BP1 protein was significantly lower when compared with patients with low/no expression. CRC, colorectal cancer; OS, overall survival; p-4E-BP1, phosphorylated 4E-binding protein 1; PTEN, phosphatase and tensin homolog.

cell survival and growth $(21,22)$. Alterations in the $\mathrm{PI} 3 \mathrm{~K} / \mathrm{AKT}$ /mTOR and Ras-Raf-extracellular signal-regulated kinase (ERK) signaling cascade pathways are frequently detected in tumors (23). The cap-dependent mRNA translation initiation complex is a final effector of these signaling cascades, and 4E-BP1 negatively regulates this complex. $4 \mathrm{E}-\mathrm{BP} 1$ promotes the expression of growth factors and survival factors. eIF4E binds to the mRNA cap structure during cap-dependent translation and promotes both ribosome binding and the formation of the eIF4F initiation complex. 
Table I. Association between p-4E-BP1 expression in colorectal cancer tissues and clinicopathological features.

\begin{tabular}{|c|c|c|c|}
\hline Characteristic & $\mathrm{n}$ & No. with high/moderate p-4E-BP1 expression (\%) & P-value \\
\hline Gender & & & 0.492 \\
\hline Male & 48 & $27(56.3)$ & \\
\hline Female & 41 & $26(63.4)$ & \\
\hline Age & & & 0.579 \\
\hline$<55$ & 34 & $19(55.9)$ & \\
\hline$\geq 55$ & 55 & $34(61.8)$ & \\
\hline Tumor location & & & 0.558 \\
\hline Proximal & 21 & $11(52.4)$ & \\
\hline Distal & 30 & $17(56.7)$ & \\
\hline Rectum & 38 & $25(65.8)$ & \\
\hline Tumor diameter $(\mathrm{cm})$ & & & 0.594 \\
\hline$<5$ & 39 & $22(56.4)$ & \\
\hline$\geq 5$ & 50 & $31(62.0)$ & \\
\hline Differentiation & & & 0.161 \\
\hline Well & 20 & $10(50.0)$ & \\
\hline Moderate & 39 & $21(53.8)$ & \\
\hline Poor & 30 & $22(73.3)$ & \\
\hline Local invasion & & & 0.251 \\
\hline $\mathrm{T} 1-2$ & 38 & $20(52.6)$ & \\
\hline $\mathrm{T} 3-4$ & 51 & $33(64.7)$ & \\
\hline Lymph metastasis & & & 0.130 \\
\hline No & 36 & $18(50.0)$ & \\
\hline Yes & 53 & $35(66.0)$ & \\
\hline TNM stage & & & 0.209 \\
\hline $\mathrm{I} / \mathrm{II}$ & 35 & $18(51.4)$ & \\
\hline III/IV & 54 & $35(64.8)$ & \\
\hline
\end{tabular}

$\chi^{2}$ test was used to identify differences in frequency. p-4E-BP1, phosphorylated 4E-binding protein 1; TMN stage, tumor node metastasis stage.

Table II. Multivariate analysis of clinicopathological features and OS of 89 patients with colorectal cancer.

\begin{tabular}{lrr}
\hline & & \multicolumn{1}{c}{ OS } \\
\cline { 2 - 3 } Variable & RR (95\% CI) & P-value \\
\hline Tumor differentiation (poor vs. moderate vs. well) & $1.778(0.732-4.321)$ & 0.202 \\
Local invasion (T3-4 vs. T1-2) & $1.725(0.736-4.043)$ & 0.208 \\
Lymph node metastasis (yes vs. no) & $2.609(1.082-6.292)$ & 0.031 \\
TNM stage (III/ IV vs. I/II) & $1.963(0.823-4.684)$ & 0.126 \\
p-4E-BP1 expression (high/moderate vs. low/negative) & $2.816(1.123-6.535)$ & 0.025 \\
\hline
\end{tabular}

Multivariate Cox proportional hazard model was used to define the potential prognostic significance of individual parameter. OS, overall survival; CRC, colorectal cancer; RR, relative risk; CI, confidence interval; TNM, tumor node metastasis classification system; p-4E-BP1, phosphorylated 4E-binding protein 1.

When active, non-phosphorylated 4E-BP1 binds to eIF4E, formation of the initiation complex is prevented. Therefore, translation is inhibited and apoptosis is initiated. However, when 4E-BP1 is phosphorylated, its binding affinity is reduced and eIF4E is released, thus initiating cap-dependent translation (24). Therefore, $\mathrm{p}-4 \mathrm{E}-\mathrm{BP} 1$ expression in tumor cells may reflect their oncogenic potential. In several human cancers, p-4E-BP1 expression was identified as being associated with 
poor prognosis. These included carcinomas of the esophagus, stomach, breast, ovary, cervix and endometrium, and in childhood rhabdomyosarcoma, hilar cholangiocarcinoma and melanoma $(6-11,25,26)$. Previous studies have indicated that $4 \mathrm{E}-\mathrm{BP} 1$ is essential for cell transformation. Transferring mutant 4E-BP1 phosphorylation sites into breast carcinoma cells was found to suppress their tumorigenicity (27). In a recent study, the expression levels of eIF4E increased gradually as CRC progressed from benign dysplasia to adenocarcinoma. However, total 4E-BP1 protein expression increased only during the premalignant state of the disease, and then decreased or ceased entirely upon malignancy (28). Therefore, 4E-BP1 demonstrates a biphasic pattern of expression during CRC carcinogenesis, and is expressed only in hyperplasic or dysplastic tissues as an endogenous tumor suppressor molecule.

The aim of the present study was to investigate the status of p-4E-BP1 expression in CRC and to establish its clinical significance. The results indicated that $\mathrm{p}-4 \mathrm{E}-\mathrm{BP} 1$ was expressed at significantly lower levels in CRC tissue samples compared with adjacent normal tissues. Increased expression of p-4E-BP1 was demonstrated to be predominant in patients with regional lymph node metastases and in poorly differentiated tumors, and was significantly associated with reduced OS. As demonstrated in previous studies of gastric and breast cancers, the results of the present study further confirmed that p-4E-BP1 may be useful in predicting the prognosis of CRC.

A number of cancers demonstrated activation of the PI3K/AKT and RAS/RAF/MEK/ERK signaling pathways. In addition, they frequently display mutations in genes that encode components of these pathways. In a number of human tumors, the AKT and ERK signaling pathways are activated concurrently by separate mutations (29). During tumorigenesis, 4E-BP1 is an effector for the oncogenic roles of ERK and AKT signaling pathways (30). In an experimental model of CRC, involving involves KRAS and PIK3CA mutations, little or no 4E-BP1 phosphorylation in response to inhibition of either ERK or AKT was observed (30). Additional studies have demonstrated that active 4E-BP1 inhibits tumorigenesis in PTEN-mutant breast cancer (31). PTEN is a tumor suppressor gene that is frequently mutated or deleted in tumor cell lines and human cancers. Results from previous studies have demonstrated that overexpression of PTEN in breast cancer cells impairs insulin-induced phosphorylation of MAPK (32). These data are consistent with the results of the current study, which demonstrated that downregulation of the PTEN protein was associated with $\mathrm{p}-4 \mathrm{E}-\mathrm{BP} 1$ upregulation in CRC samples. Together, these data suggest that 4E-BP1 phosphorylation may the result of different oncogenic events associated with biochemical pathways, including those associated with growth factor receptors, loss of function mutations or mutations in p53, PTEN, RAS and PI3K, and additional mechanisms associated with cellular oncogenic activation. As there are numerous genetic alterations that affect 4E-BP1, the phosphorylated form of 4E-BP1 may function as an inhibitor of the transforming signals, channeling the oncogenic proliferative signal independently of any upstream-specific oncogenic alterations. Further studies are required to identify the mechanisms by which 4E-BP1 affects the development and progression of CRC.

\section{References}

1. Torre LA, Bray F, Siegel RL, Ferlay J, Lortet-Tieulent J and Jemal A: Global cancer statistics, 2012. CA Cancer J Clin 65: 87-108, 2015.

2. Saif MW and Chu E: Biology of colorectal cancer. Cancer J 16: 196-201, 2010.

3. Armengol G, Rojo F, Castellvi J, Iglesias C, Cuatrecasas M, Pons B, Baselga J and Ramón y Cajal S: 4E-binding protein 1: A key molecular 'funnel factor' in human cancer with clinical implications. Cancer Res 67: 7551-7555, 2007.

4. Magagnin MG, van den Beucken T, Sergeant K, Lambin P, Koritzinsky M, Devreese B and Wouters BG: The mTOR target 4E-BP1 contributes to differential protein expression during normoxia and hypoxia through changes in mRNA translation efficiency. Proteomics 8: 1019-1028, 2008.

5. Barnhart BC, Lam JC, Young RM, Houghton PJ, Keith B and Simon MC: Effects of 4E-BP1 expression on hypoxic cell cycle inhibition and tumor cell proliferation and survival. Cancer Biol Ther 7: 1441-1449, 2008.

6. Rojo F, Najera L, Lirola J, Jiménez J, Guzmán M, Sabadell MD Baselga $J$ and Ramon y Cajal S: 4E-binding protein 1, a cell signaling hallmark in breast cancer that correlates with pathologic grade and prognosis. Clin Cancer Res 13: 81-89, 2007.

7. Castellvi J, Garcia A, Rojo F, Ruiz-Marcellan C, Gil A, Baselga J and Ramon y Cajal S: Phosphorylated 4E binding protein 1: A hallmark of cell signaling that correlates with survival in ovarian cancer. Cancer 107: 1801-1811, 2006.

8. Benavente S, Vergés R, Hermosilla E, Fumanal V, Casanova N, García A, Ramón Y Cajal S and Giralt J: Overexpression of phosphorylated 4E-BP1 predicts for tumor recurrence and reduced survival in cervical carcinoma treated with postoperative radiotherapy. Int J Radiat Oncol Biol Phys 75: 1316-1322, 2009.

9. Castellvi J, Garcia A, Ruiz-Marcellan C, Hernández-Losa J, Peg V, Salcedo M, Gil-Moreno A and Ramon y Cajal S: Cell signaling in endometrial carcinoma: Phosphorylated 4E-binding protein-1 expression in endometrial cancer correlates with aggressive tumors and prognosis. Hum Pathol 40: 1418-1426, 2009.

10. Yeh CJ, Chuang WY, Chao YK, Liu YH, Chang YS, Kuo SY, Tseng CK, Chang HK and Hsueh C: High expression of phosphorylated 4E-binding protein 1 is an adverse prognostic factor in esophageal squamous cell carcinoma. Virchows Arch 458: 171-178, 2011.

11. Jiao X, Pan J, Qian J, Luo T, Wang Z, Yu G and Wang J: Overexpression of $\mathrm{p}-4 \mathrm{ebp} 1$ in Chinese gastric cancer patients and its correlation with prognosis. Hepatogastroenterology 60: 921-926, 2013.

12. Edge SB, Byrd DR, Compton CC, Fritz AG, Greene FL and Trotti A: editors. AJCC cancer staging manual. 7th ed. New York: Springer; 2010.

13. Ueno H, Kajiwara Y, Shimazaki H, Shinto E, Hashiguchi Y, Nakanishi K, Maekawa K, Katsurada Y, Nakamura T, Mochizuki $\mathrm{H}$, et al: New criteria for histologic grading of colorectal cancer. Am J Surg Pathol 36: 193-201, 2012.

14. Rousseau B, Chibaudel B, Bachet JB, Larsen AK, Tournigand C, Louvet C, André T and de Gramont A; GERCOR (French Oncology Research Group): Stage II and stage III colon cancer: Treatment advances and future directions. Cancer J 16: 202-209, 2010.

15. De Sousa E Melo F, Vermeulen L, Fessler E and Medema JP: Cancer heterogeneity-a multifaceted view. EMBO Rep 14: 686-695, 2013.

16. Walker AS, Johnson EK, Maykel JA, Stojadinovic A, Nissan A, Brucher B, Champagne BJ and Steele SR: Future directions for the early detection of colorectal cancer recurrence. J Cancer 5: 272-280, 2014

17. Sinicrope FA and Sargent DJ: Molecular pathways: Microsatellite instability in colorectal cancer: Prognostic, predictive, and therapeutic implications. Clin Cancer Res 18: 1506-1512, 2012.

18. Roth AD, Tejpar S, Delorenzi M, Yan P, Fiocca R, Klingbiel D, Dietrich D, Biesmans B, Bodoky G, Barone C, et al: Prognostic role of KRAS and BRAF in stage II and III resected colon cancer: Results of the translational study on the PETACC-3, EORTC 40993, SAKK 60-00 trial. J Clin Oncol 28: 466-474, 2010.

19. Watanabe T, Kobunai T, Yamamoto Y, Matsuda K, Ishihara S, Nozawa $\mathrm{K}$, Yamada $\mathrm{H}$, Hayama T, Inoue E, Tamura J, et al: Chromosomal instability (CIN) phenotype, CIN high or CIN low, predicts survival for colorectal cancer. J Clin Oncol 30: 2256-2264, 2012. 
20. O'Connell MJ, Lavery I, Yothers G, Paik S, Clark-Langone KM, Lopatin M, Watson D, Baehner FL, Shak S, Baker J, et al: Relationship between tumor gene expression and recurrence in four independent studies of patients with stage II/III colon cancer treated with surgery alone or surgery plus adjuvant fluorouracil plus leucovorin. J Clin Oncol 28: 3937-3944, 2010.

21. Heesom KJ, Gampel A, Mellor H and Denton RM: Cell cycle-dependent phosphorylation of the translational repressor eIF-4E binding protein-1 (4E-BP1). Curr Biol 11: 1374-1379, 2001

22. Topisirovic I, Ruiz-Gutierrez M and Borden KL: Phosphorylation of the eukaryotic translation initiation factor eIF4E contributes to its transformation and mRNA transport activities. Cancer Res 64: 8639-8642, 2004

23. Halilovic E, She QB, Ye Q, Pagliarini R, Sellers WR, Solit DB and Rosen N: PIK3CA mutation uncouples tumor growth and cyclin D1 regulation from MEK/ERK and mutant KRAS signaling. Cancer Res 70: 6804-6814, 2010.

24. Averous J and Proud CG: When translation meets transforma-tion: The mTOR story. Oncogene 25: 6423-6435, 2006.

25. Petricoin EF III, Espina V, Araujo RP, Midura B, Yeung C, Wan X, Eichler GS, Johann DJ Jr, Qualman S, Tsokos M, et al: Phosphoprotein pathway mapping: Akt/mammalian target of rapamycin activation is negatively associated with childhood rhabdomyosarcoma survival. Cancer Res 67: 3431-3440, 2007.

26. O'Reilly KE, Warycha M, Davies MA, Rodrik V, Zhou XK Yee H, Polsky D, Pavlick AC, Rosen N, Bhardwaj N, et al: Phosphorylated 4E-BP1 is associated with poor survival in melanoma. Clin Cancer Res 15: 2872-2878, 2009.
27. Avdulov S, Li S, Michalek V, Burrichter D, Peterson M, Perlman DM, Manivel JC, Sonenberg N, Yee D, Bitterman PB and Polunovsky VA: Activation of translation complex eIF4F is essential for the genesis and maintenance of the malignant phenotype in human mammary epithelial cells. Cancer Cell 5: 553-563, 2004.

28. Diab-Assaf M, Abou-Khouzam R, Saadallah-Zeidan N, Habib K, Bitar N, Karam W, Liagre B, Harakeh S and Azar R: Expression of eukaryotic initiation factor $4 \mathrm{E}$ and $4 \mathrm{E}$ binding protein 1 in colorectal carcinogenesis. Int J Clin Exp Pathol 8: 404-413, 2015.

29. Simi L, Pratesi N, Vignoli M, Sestini R, Cianchi F, Valanzano R, Nobili S, Mini E, Pazzagli M and Orlando C: High-resolution melting analysis for rapid detection of KRAS, BRAF, and PIK3CA gene mutations in colorectal cancer. Am J Clin Pathol 130: 247-253, 2008.

30. She QB, Halilovic E, Ye Q, Zhen W, Shirasawa S, Sasazuki T, Solit DB and Rosen N: 4E-BP1 is a key effector of the oncogenic activation of the AKT and ERK signaling pathways that integrates their function in tumors. Cancer Cell 18: 39-51, 2010.

31. Hsieh AC, Costa M, Zollo O, Davis C, Feldman ME, Testa JR, Meyuhas O, Shokat KM and Ruggero D: Genetic dissection of the oncogenic mTOR pathway reveals druggable addiction to translational control via 4EBP-eIF4E. Cancer Cell 17: 249-261, 2010.

32. Weng LP, Smith WM, Brown JL and Eng C: PTEN inhibits insulin-stimulated MEK/MAPK activation and cell growth by blocking IRS-1 phosphorylation and IRS-1/Grb-2/Sos complex formation in a breast cancer model. Hum Mol Genet 10: 605-616, 2001. 